\title{
A Publicidade do Medicamento na Europa e seus Reflexos no Ordenamento Jurídico Português ${ }^{(*)}$
}

\author{
DRUGS ADVERTISING IN EUROPE AND ITS REFLEXIONS \\ ON THE PORTUGUESE BODY OF LAWS
}

Mário Frota ${ }^{(1)}$

\section{RESUMO}

O tema da publicidade na área da Saúde é bastante polêmico. No âmbito da Comunidade Européia, existe uma série de diretrizes sobre o assunto, as quais devem ser internalizadas pelos Estados-membros em seus ordenamentos jurídicos. No artigo em questão, analisa-se em especial a influência dessas diretrizes no conjunto das leis Portuguesas. O trabalho avalia os tipos de publicidade, os alvos aos quais elas se dirigem, suas normas e condicionantes, passando desde a distribuição de amostras até questões relativas à comunicação médica.

\section{Palavras-chave}

Comunidade Européia; Medicamentos; Portugal; Publicidade.

\section{ABSTRACT}

The subject of the advertising in the area of the Health is sufficiently controversial. In the scope of the European Community, there are several orientations regarding this subject, which must be adopted by the Nation.

(*) Nota do editor. artigo publicado originariamente em Português lusitano.

(1)Fundador e primeiro presidente da AIDC - Associação Internacional de Direito do Consumo; Fundador e primeiro vice-presidente da AEDPh - Association Européenne de Droit Pharmaceutique; Fundador e presidente do CEDC - Centro de Estudos de Direito do Consumo; Primeiro Presidente eleito do Conselho Nacional da Publicidade do Medicamento (Portugal); Professor da Faculté de Droit à I'Université de Paris XII (Créteil) ; Director da RPDC - Revista Portuguesa de Direito do Consumo; Fundador e presidente da Comissão de Instalação do Centro Ibero-Americano de Estudos de Direito do Consumidor. E-mail: <apdc.cedc@mail.telepac.pt>. 
This article analyzes the influence of these rules in the Portuguese legislation. This work also evaluates the differents kinds of advertising, including its targets, rules and limitations, since the distribution of free samples to the questions related to the medical communication.

\section{Key words}

Advertising; Drugs; European Comunity; Portugal.

\section{I - GENERALIDADES}

O tema é em si controverso, tanto mais que o medicamento é, em princípio, um produto ético insusceptível de se confundir com os produtos e serviços em geral disponíveis no mercado. Mas - mais por razões de natureza mercadológica que de saúde pública - a dicotomia medicamentos sujeitos (obrigatoriamente) à prescrição clínica e não sujeitos a tal (a receita médica) perturba a percepção dos termos da questão. Os Códigos da Publicidade, ou as leis que regem em domínio tão sensivel das relações entre empresas e consumidores, proclamam a uma: "é proibida a publicidade a medicamentos e a tratamentos médicos". Porque se entende exactamente que se trata de um segmento relevante da saúde pública e que interesses mercantis - sejam de que espécie(2) forem - jamais poderão afectar ou afrontar. O facto é que os fármacos não são em si inócuos e, por conseguinte, nem sempre, de uma perspectiva científica, se justifica a fractura conceptual entre medicamentos sujeitos e não sujeitos à prescrição médica. Tanto mais quanto medicamentos fundados em um mesmo princípio activo figuram com nomes de fantasia distintos em ambas as listas, o que é fruto ou da incúria dos governos que as convertem em lei ou da distraç̧ão dos sábios de cuja pena emanam as propostas de constituição das tabelas a que os medicamentos se adscrevem.

A Directiva n. 92/28/CEE, do Conselho, de 31 de março de 1992, estabeleceu na Comunidade Européia, pela vez primeira, o regime jurídico da publicidade dos medicamentos para uso humano.

Cerca de uma década depois, a Directiva n. 2001/83/CE, do Parlamento Europeu e do Conselho, de 6 de novembro de 2001, revogou o anterior instru-

(2) $O$ art. 152 do Tratado da União Européia define exactamente que "A fim de promover os interesses dos consumidores e assegurar um elevado nivel de defesa destes, a Comunidade contribuirá para a proteç̧ão da saúde, da segurança e dos interesses económicos dos consumidores, bem como para a promoção do seu direito à informação, à educação e à organização para a defesa dos seus interesses". 
mento normativo, codificando as normas aplicáveis aos medicamentos ${ }^{(3)}$, inscrevendo o regime da publicidade que thes quadra nos seus arts. 86 a $100^{(4)}$.

As directivas, conquanto emanadas das instâncias legiferantes da União Européia, carecem, porém - para que se imponham na ordem interna de cada um dos Estados -, de um processo normativo de transposição. Tal processo, a desencadear intra muros (a União Européia está ainda distante do modelo federalista que tantos advogam como figurino político desejável) ${ }^{(5)}$, é imprescindivel para que as normas se tornem, em princípio, efectivas e vinculem os seus destinatários no espaço jurídico de que se trata.

O regime aprovado pela directiva por último enunciada, e que recobre em geral as regras da que a precedeu, não se aplica: à rotulagem e ao folheto informativo (bula) que acompanham os medicamentos para uso humano; à correspondência, a que se anexe eventual documento de pendor não publicitário, necessária à resposta a uma pergunta especifica sobre determinado medicamento; às informações concretas e aos documentos de referência susceptíveis de concretizar alterações de embalagem, às advertências sobre efeitos adversos no âmbito da farmacovigilância, bem como aos catálogos de venda e às listas de preços, desde que não contenham informação sobre o medicamento e às informações relativas à saúde humana ou a doenças humanas, desde que não façam referência, ainda que de forma indirecta, a um medicamento.

(3) A Directiva n. 2001/83/CE, de 6 de novembro de 2001, foi transposta para a ordem jurídica portuguesa pelo DL n. 176/2006, de 30 de agosto pretérito, aí se coligindo a legislação mais pertinente ao medicamento.

(4) A Directiva, nos seus consideranda, reflecte a idéia de que os "Estados-membros adoptaram medidas especificas relativas à publicidade ... a medicamentos [:] registram-se disparidades entre tais medidas [;] essas disparidades têm repercussões no funcionamento do mercado interno, na medida em que a publicidade difundida num Estado-membro pode produzir efeitos nos outros Estados-membros". E no considerandum imediato - o (44) - regista: "A Directiva 89/552/CEE, do Conselho, de 3 de outubro de 1989, relativa à coordenação de certas disposições legislativas, regulamentares e administrativas dos Estados-membros [atinentes] ao exercício de actividades de radiodifusão televisiva, proibe a publicidade televisiva de medicamentos que apenas sejam "vendidos" mediante receita médica no Estado-membro a cuja esfera de competência pertence o organismo de radiodifusão televisiva. Justifica-se generalizar este princípio, tornando-o extensivo a outros meios de comunicação". O propósito é, pois, o de harmonizar as regras vertidas em cada um dos ordenamentos jurídicos (que não uniformizar, como se tem por pacífico, porque, a ser assim, o figurino normativo seria o do regulamento que não o da directiva), conquanto neste particular, a não haver uma mesma bitola para a aferição das listas de medicamentos sujeitos e não sujeitos à prescrição médica obrigatória, o que num dos Estados-membros figura no rol dos sujeitos a receita, noutro pode bem constar da lista dos não sujeitos a prescrição imperativa. $O$ que em termos de publicidade transfronteiras pode originar sérias perturbações. Curial seria que as listas fossem concertadas no seio da Agência Européia do Medicamento por forma a obviar as disparidades observadas no quotidiano.

(5) De qualquer sorte, haveria sempre a hipótese de uniformizar o regime do medicamento na União Européia, através de regulamentos aplicáveis a todos os Estados-membros sem que de modo directo e imediato haja a possibilidade de alteração unilateral das regras por cada um dos aludidos Estados. 


\section{II - A PUBLICIDADE DO MEDICAMENTO "STRICTO SENSU"}

Considera-se, porém, publicidade dos medicamentos "qualquer acção de comunicação, de informação, de prospeç̧ão ou de incentivo destinada a promover a sua prescrição, dispensa, venda ou consumo".

Abrange, em especial, a publicidade dos medicamentos junto do público em geral(6) e das pessoas habilitadas a receitá-los ou a fornecê-los; a visita de delegados de propaganda médica a pessoas habilitadas a receitar ou a fornecer medicamentos; o fornecimento de amostras de medicamentos; o incentivo à prescrição ou ao fornecimento de medicamentos, através da concessão, oferta ou promessa de benefícios pecuniários ou em espécie, excepto quando o seu valor intrínseco seja insignificante; o patrocínio de reuniões de promoção a que assistam pessoas habilitadas a receitar ou a fornecer medicamentos e o patrocínio de congressos científicos em que participem pessoas habilitadas a receitar ou a fornecer medicamentos, nomeadamente a tomada a cargo das respectivas despesas de deslocação e estadia nessa ocasião.

No plano das proibições ou das restrições, assinale-se que a publicidade dos medicamentos inclui a proibição da publicidade de medicamentos cuja autorização de introdução no mercado não haja sido concedida e a proibição condicionada de publicidade de medicamentos cuja dispensa dependa obrigatoriamente de receita médica (a proibição é, porém, relativa). As restrições também atingem, inexoravelmente, a publicidade que haja por universo-alvo o grande público; admite-se, porém, em publicações técnicas ou em suportes de informação exclusivamente destinados aos facultativos (médicos) ou aos mais profissionais da saúde.

A publicidade, contudo, qualquer que seja (tomando por base os medicamentos sujeitos ou não imperativamente à receita médica) acha-se condicionada a um sem-número de restrições, tais como: deve promover o uso racional dos medicamentos, fazendo-o de forma objectiva e sem que se exagere as suas propriedades; ser concebida de maneira que a mensagem publicitária apareça claramente expressa, indicando tratar-se de um medicamento; não pode divergir das informações constantes do resumo das características do medicamento, tal como foi autorizado; não pode ser enganosa.

A publicidade que os laboratórios de especialidades farmacêuticas, ou quaisquer outros operadores, intentem efectuar - e que se destina ao universo de consumidores - tem de oferecer uma série de elementos, como o nome do medicamento (bem como a denominação comum, caso o me-

(6) No que tange à denominada publicidade "grande público", pondera-se no preâmbulo da Directiva que "A publicidade junto do público em geral de medicamentos [dispensados] sem receita médica poderia afectar a saúde pública se fosse excessiva e irreflectida. Tal publicidade, quando da sua autorização, deve portanto satisfazer determinados critérios essenciais, que importa definir". E no corpo da directiva avultam os critérios cuja observância se impõe e de que o texto se faz eco. 
dicamento contenha apenas uma substância activa), as indicações terapêuticas e precauções especiais e outras informações indispensáveis ao uso adequado do medicamento, além de aconselhamento ao utente para ler cuidadosamente as informações constantes da embalagem externa ou do folheto informativo e, em caso de dúvida, consultar o médico se persistirem os sintomas.

A publicidade carreada, porém, aos facultativos, ou seja, aos prescritores terá de incluir, imperativamente, um resumo das características do medicamento, sua classificação para efeitos de dispensa (nomeadamente a indicação de prescrição médica obrigatória, se for, caso disso), além do preço das várias apresentações e o regime de comparticipação.

Se for medicamento susceptivel de comparticipação, os valores suportados pela administração pública e pelo consumidor ter-se-ão de discriminar em moeda com curso legal, atentos os distintos regimes de comparticipação.

No que tange, porém, à publicidade que por alvo tiver o universo de consumidores, há elementos que, de todo, o regime em vigor veda(7). $\mathrm{Na}$ realidade, a lei coíbe que as mensagens contenham elementos que levem a concluir que a consulta médica ou a intervenção cirúrgica é desnecessária, em particular sugerindo um diagnóstico ou preconizando o tratamento por correspondência. Também proíbe mensagens que sugiram que o efeito do medicamento é garantido, sem reações secundárias, com resultados superiores ou equivalentes aos de outro tratamento ou medicamento ou que

(7) A publicidade dos medicamentos homeopáticos está sujeita de análogo modo às disposições que se aplicam aos medicamentos em geral, ainda que não haja AIM. No entanto, na publicidade de tais medicamentos só se pode usar os elementos que se exige para a rotulagem, eventualmente, para a bula, como segue: denominação científica da(s) matéria(s)-prima(s), seguida do grau de diluição, utilizando os símbolos da farmacopéia adoptada, de acordo com o $\mathrm{n}$. 5 do art. 1․, nome e endereço do titular do registo e, se for caso disso, do fabricante, modo de administração e, se necessário, via de administração, prazo de validade explícito (mês, ano), forma farmacêutica, capacidade do modelo para venda, precauções específicas de conservação, se for caso disso, advertência especial no caso de o medicamento assim o exigir, número do lote de fabrico, número de registo, "medicamento homeopático sem indicações terapêuticas aprovadas", aviso aconselhando o paciente a consultar o médico se persistirem os sintomas durante a utilização do medicamento. É lícito, porém, aos Estados-membros proibir, nos termos de art. 100 da Directiva n. 2001/83/CE, do Parlamento Europeu e do Conselho, de 6 de novembro de 2001, qualquer tipo de publicidade aos medicamentos homeopáticos para os quais não se haja criado um processo de registo simplificado especial. No entanto, assinale-se que só se acham sujeitos a um processo de registo simplificado especial os medicamentos homeopáticos que preencham cumulativamente as condições a seguir enunciadas: via de administração oral ou externa, ausência de indicações terapêuticas especiais no rótulo ou em qualquer informação relativa ao medicamento, grau de diluição que garanta a inocuidade do medicamento; em especial, o medicamento não pode conter nem mais de uma parte por 10.000 da tintura-mãe nem mais de 1/100 da mais pequena dose eventualmente utilizada em alopatia para as substâncias activas cuja presença num medicamento alopático acarrete a obrigação de apresentar uma receita médica. 
sugiram que o estado normal de saúde da pessoa possa ser melhorado através da utilização do medicamento ou que possa ser prejudicado caso o medicamento não seja utilizado, excepto no que diga respeito às campanhas de vacinação.

Além disso, são vedadas mensagens que se dirijam exclusiva ou principalmente a crianças; que façam referência a uma recomendação emanada por cientistas, profissionais de saúde ou outra pessoa que, pela sua celebridade, possa incitar ao consumo de medicamentos; tratem o medicamento como um produto alimentar, cosmético ou qualquer outro produto de consumo; que sugiram que a segurança ou eficácia do medicamento é devida ao facto de ser considerado um produto natural; que possam induzir, por uma descrição ou representação detalhada da anamnese, a um falso autodiagnóstico; que se refiram de forma abusiva, assustadora ou enganosa a demonstrações ou garantias de cura; que utilizem de forma abusiva, assustadora ou enganosa representações visuais das alterações do corpo humano causadas por doenças ou lesões, ou da acção de um medicamento no corpo humano ou em partes do corpo humano e que refiram que o medicamento recebeu uma autorização de introdução no mercado.

No entanto, veda ainda a norma européia que se insiram indicações terapêuticas susceptíveis de conduzir os destinatários à automedicação, em particular de patologias como tuberculose; doenças transmitidas sexualmente; outras doenças infecciosas graves; câncer e outras doenças tumorais; insônia crônica; diabetes e outras doenças do metabolismo.

Proíbe-se ainda na publicidade dirigida ao grande público os medicamentos em cuja composição se integrem estupefacientes ou substâncias psicotrópicas.

A publicidade comparativa, porém, que a ordem jurídica da União Européia ora admite - e o facto remonta a $1997^{(8)}$ - é vedada sob qualquer das formas susceptíveis de se revestir.

(8) A Directiva CE n. 97/55/CE, de 6 de outubro, do Parlamento Europeu e do Conselho, que introduziu modificações na Directiva n. 84/450/CEE, do Conselho, de 10 de setembro de 1984, aditou 0 art. $3^{\circ}$-A, em que se consagra a admissibilidade, em geral, da publicidade comparativa, em dados termos, a saber: "1. A publicidade comparativa é autorizada, no que se refere exclusivamente à comparação, quando se reúnam as seguintes condições:a) Não ser enganosa nos termos do n. 2 do art. $2^{\circ}$, do art. $3^{\circ}$ e do $n .1$ do art. $7^{\text {; }}$ b) Comparar bens ou serviços que respondem às mesmas necessidades ou têm os mesmos objectivos; c) Comparar objectivamente uma ou mais caracteristicas essenciais, pertinentes, comprováveis e representativas desses bens e serviços, entre as quais se pode incluir o preço; d) Não gerar confusão no mercado entre o anunciante e um concorrente ou entre as marcas, designações comerciais, outros sinais distintivos, bens ou serviços do anunciante e do concorrente; e) Não desacreditar ou depreciar marcas, designações comerciais, outros sinais distintivos, bens, serviços, actividades ou situação de um concorrente; f) Referir-se, em todos os casos de produtos com denominação de origem, a produtos com a mesma denominação; g) Não retirar partido indevido do renome de uma marca, designação comercial ou outro sinal distintivo de um concorrente ou da denominação de origem de produtos concorrentes; h) Não apresentar um bem ou serviço como sendo imitação ou reprodução de um bem ou serviço cuja marca 


\section{III - A PROMOÇÃo ATRAVÉS de AMOSTRAS}

De modo análogo, a publicidade - ou antes, a promoção - assente na distribuição gratuita de medicamentos é proibida se se tratam de amostras dirigidas aos consumidores ${ }^{(9)}$. As amostras gratuitas restringir-se-ão, a título excepcional, aos facultativos habilitados a prescrever, sujeitando-se, porém, uma tal faculdade a um sem-número de pressupostos. Só podem, pois, ser cedidas, se observadas as condições seguintes:

- um número limitado de amostras de cada medicamento por ano e por técnico habilitado a prescrever, a definir na autorização de introdução no mercado do medicamento;

- serem objecto de pedido escrito, datado e assinado, feito pelo destinatário;

- não serem superiores à apresentação de menor dimensão que for comercializada;

- conterem a menção "amostra gratuita" e "proibida a venda ao público", ou outras semelhantes.

As amostras de medicamentos sujeitos à receita médica só podem ser cedidas durante os dois anos subseqüentes à data da introdução no mercado. Não poderão, porém, ser cedidas amostras de medicamentos que contenham estupefacientes ou substâncias psicotrópicas. As entidades que entendem ceder amostras gratuitas deverão adoptar um sistema adequado susceptivel de assegurar e garantir um controle irrestrito e a inerente responsabilidade (que pode assumir, como no caso português, a feição de ilícitos de mera ordenação social passiveis de coimas de carácter pecuniário, sem deixar de se considerar a sanção acessória da inibição de publicidade do medicamento até dois anos). Sem que se observe o ne bis in idem, a responsabilidade contra-ordenacional não prejudica a responsabilidade disciplinar que ao caso couber.

ou designação comercial seja protegida. 2. Qualquer comparação que faça referência a uma oferta especial deve indicar de forma clara e inequivoca o seu termo ou, se necessário, que essa oferta especial depende da disponibilidade dos produtos ou serviços; quando a oferta especial ainda não se tenha iniciado, a data de início do periodo durante o qual é aplicável o preço especial ou qualquer outra condição específica deve também ser indicada."

(9) A proibição de amostras gratuitas aos consumidores em geral para efeitos de promoção do medicamento é, pois, vedada expressamente, apenas se consentindo, nos limites estreitos definidos no art. 96 da Directiva, a sua outorga aos prescritores desde que legalmente habilitados a fazê-lo. No mais, as restrições e ou proibições neste passo contidas equivalem-se às prescrições constantes dos códigos auto-regulatórios a que noutro ponto se fará referência (cf. infra VII). Vide, porém, no que toca à dispensa de amostras gratuitas aos facultativos, o considerandum 51 , segundo o qual "importa que possam ser fornecidas amostras gratuitas de medicamentos, observando determinadas condições restritivas, às pessoas habilitadas a receitar ou fornecer medicamentos, por forma a que se familiarizem com os novos medicamentos e adquiram experiência da sua utilização". 


\section{IV - A PUBLICIDADE DO MEDICAMENTO UNIVERSO-ALVO: MÉDICOS E FARMACÊUTICOS}

A publicidade dirigida aos médicos e a mais técnicos qualificados ${ }^{(10)}$ é mister que inclua, como se assevera, determinados elementos, além de dever ser observado um sem-número de requisitos, no que tange à documentação para facultativos e farmacêuticos:

A documentação que seja transmitida como promoção destinada a técnicos habilitados a prescrever ou a dispensar medicamentos deve incluir, no mínimo, as informações essenciais que se compaginem com:

- o resumo das características do produto;

- a classificação do medicamento para efeitos de fornecimento;

- eventualmente, o preço de venda ou a tarifa indicativa das várias formas de apresentação; e

- as condições de reembolso pelos organismos de segurança social.

Além de indicar a data em que foi estabelecida ou revista pela última vez.

A informação contida na documentação referida no passo precedente deve ser exacta, actual, verificável e suficientemente completa para permitir ao destinatário fazer uma idéia correcta do valor terapêutico do medicamento. Já, as citações e o material ilustrativo retirados de publicações médicas, ou trabalhos científicos que se destinem a ser usados na documentação prevista neste particular, devem ser correctamente reproduzidos e indicada a respectiva fonte.

\section{Informação e seus pressupostos}

A informação do medicamento, que se mescla neste passo com a publicidade, conquanto de domínios distintos se trate, assume peculiar relevância neste congenho.

Neste passo avulta, pois, quer um amálgama de responsabilidades funcionais do titular da autorização de introdução no mercado, como da empresa responsável no mercado em geral pela promoção do medicamento(11).

(10) No particular da publicidade de medicamentos no círculo dos que se achem habilitados a prescrever ou dispensar, realce para a proposição segundo a qual - considerandum (47) - tal "contribui para a [sua] informação: importa, todavia, submetê-la a condições estritas e a um controlo efectivo, com base nomeadamente nos trabalhos efectuados no âmbito do Conselho da Europa".

(11) Aí os instrumentos normativos dispõem que: "O titular da autorização de introdução no mercado ou a empresa responsável pela promoção do medicamento devem manter um serviço científico responsável pela informação relativa aos medicamentos que colocam no mercado, o qual deve dispor de toda a informação cientifica relativa aos mesmos e à publicidade realizada, em fichas que mencionam os destinatários, modo e data da primeira difusão". 
Os promotores de informação médica, vulgo, os delegados funcionalmente dependentes dos laboratórios da indústria farmacêutica, devem, porém, dispor de formação científica adequada e de saberes bastantes que Ihes permitam fornecer pontualmente informações precisas e tão completas quanto possivel sobre os medicamentos que Ihes cumpre apresentar aos técnicos habilitados a prescrever e a dispensar.

Aos delegados de informação médica incumbe apresentar aos facultativos visitados (e a quem habilitado se ache a prescrever) ou tornar disponível o resumo das características de cada um dos fármacos apresentados, informações sobre os preços praticados e, se for o caso, as condições de comparticipação da administração pública.

Aos delegados compete ainda - no quadro, de resto, das funções de farmacovigilância que ora lhes cabem também, ainda que de modo residual, que não de menor relevância - transmitir ao departamento científico do laboratório de produtos farmacêuticos que representam, quaisquer informações acerca do uso dos medicamentos que promovem, em particular no que se prende com as reacções adversas que cheguem à sua esfera de conhecimento pelo contacto pessoal com os facultativos e outros profissionais de saúde.

Trata-se de uma função relevante que se assaca, em particular, aos delegados de informação médica pela posição privilegiada que assumem neste congenho, e que não pode ser descurada, em homenagem à saúde pública que mister é assuma a relevância que se lhe reconhece no quadro da protecção do consumidor, como em outro passo se assinalou.

A exigência de um tal dever funcional, se negligenciada, é susceptivel de importar, consoante os casos, responsabilidade penal ou disciplinar.

\section{V - A PROBLEMÁTICA DOS PRÊMIOS, OFERTAS E OUTROS BENEFÍCIOS}

Sucessivos escândalos que envolveram farmacêuticas (laboratórios de especialidades farmacêuticas) e médicos de distintas formações impuseram que em um sem-número de países se disciplinasse de forma estrita um tal domínio, de molde a obviar às distorções que situações de análogo jaez inevitavelmente acarretam ${ }^{(12)}$.

(12) Como alude um articulista - SANTOS, Beja. Diário de Aveiro, ed. $1^{\circ}$ set: "Não é de ontem que surgem críticas aos comportamentos menos éticos de uma boa parte da indústria farmacêutica. Quem ler "O Grande Segredo da Indústria Farmacêutica" (por Philippe Pignarre, Campo da Comunicação, 2004) verificará a consistência de queixas a procedimentos lesivos do dinheiro público e das expectativas dos doentes: medicamentos iguais vendidos com comparticipação ou não prescritos, com o apoio das autoridades nacionais para aligeirar a factura da Segurança Social, fidelização do prescritor através de compensações aos médicos; crescimento 
Daí que se haja regrado segmentos como os dos prêmios, ofertas ou brindes, o da participação em eventos científicos e profissionais e as acções de promoção de medicamentos, precisando-se o conceito de custos e acolhimento dos profissionais de saúde, maxime dos discipulos de Hipócrates, amiúde assediados pelas farmacêuticas no quadro, afinal, da promoção dos medicamentos e em vista de uma prescrição maciça ${ }^{(13)}$.

das relações promiscuas entre a imprensa, congressos e laboratórios farmacêuticos; desenvolvimento de campanhas de saúde pública determinam na consulta médica e na toma de medicamentos; financiamento de conferências e reuniões em temas onde a indústria julgue ir obter idéias para cativar os poderes públicos e a classe médica (caso do tratamento da esquizofrenia). Recorde-se que o mais importante inquérito em Portugal depois do 25 de abril, ainda não concluído, incide sobre as relações promíscuas entre os médicos e os laboratórios. Vale a pena ler o livro do Prof. Pignarre para conhecer melhor as estratégias comerciais dos laboratórios. A Consumers International, Federação de Organização de Consumidores, que se consagra à escala mundial na promoção desta política de desenvolvimento humano, com o apoio da Direç̧ão-Geral do Emprego da União Européia, procedeu a um estudo sobre o marketing da indústria farmacêutica que acaba de ser publicado sob o título "As Receitas-Milagre dos Laboratórios: o ponto de vista dos consumidores sobre a responsabilidade social, a promoção dos medicamentos e a indústria farmacêutica na Europa". O acesso à versão integral do estudo pode ser feito no site www.consumersinternational.org/pharma<http:// www.consumersinternational.org/pharma>. Os elementos que aqui se avançam reflectem os principais problemas detectados pela Consumers International. A promoção dos medicamentos preocupa os consumidores, já que é público e notório uma série de situações em que o marketing afecta a saúde, pode induzir o aumento indevido do consumo de medicamentos, gera opacidade de mercado, manipulação da prescrição médica e lesões profundas ao principio da informação objectiva do doente $e$ do utente de saúde. Dentro dessas situações temos o caso do Vioxx, um poderoso analgésico fabricado pela Merck em que se veio a apurar que o laboratório já estava há vários anos ao corrente das reacções adversas, tendo manipulado estudos em revistas científicas, a ponto de manipular informações sobre os efeitos cardiovasculares do medicamento. Este caso faz destacar a falta de ética na promoção dos medicamentos, impedindo a informação segura e levando a mortes e sofrimentos evitáveis. No anexo do estudo, que envolve os laboratórios mais representativos que operam no território da União Européia, o leitor encontrará irregularidades nos comportamentos de laboratórios tais como AstraZeneca, Boehringer Ingelheim, BMS, Eli Lilly, Johnson \& Johnson ou Novartis."

(13) No que em particular se prende com os estimulos ou incentivos facultados a prescritores e a quem incumba a dispensa de medicamentos nos espaços próprios - farmácias de oficina ou outros -, o considerandum (50) é expresso em consignar que "as pessoas habilitadas a receitar medicamentos devem ser capazes de exercer essas funções com toda a objectividade, sem serem influenciadas por estímulos financeiros directos ou indirectos". E no corpo da Directiva sobressai dos arts. 94 e ss. disciplina específica a um tal propósito. Contemplemos o art. 94: "1. No âmbito da promoção de medicamentos junto das pessoas habilitadas para os receitar ou fornecer, é proibido conceder, oferecer ou prometer a essas pessoas quaisquer prêmios, benefícios pecuniários ou benefícios em espécie, excepto quando se trate de objectos de valor insignificante e não estejam relacionados com a prática da medicina ou da farmacologia. 2. Nas acções de promoção de vendas, o acolhimento deve ser sempre de nivel razoável e ter um carácter acessório em relação ao objectivo principal da reunião; não pode ser alargado a pessoas que não sejam profissionais da saúde. 3. As pessoas habilitadas a receitar ou fornecer medicamentos não podem solicitar nem aceitar qualquer dos incentivos proibidos por força do $n$. 1 ou contrários ao n. 2. 4. As medidas ou práticas comerciais existentes nos Estados-Membros em matéria de preços, margens e descontos não são afectadas pelos ns. 1, 2 e 3." E o que no art. 95 se plasma: "O disposto no $n$. 1 do art. 94ำ não obsta ao acolhimento de forma directa ou indirecta, em manifestações de carácter exclusivamente profissional e cientifico; esse acolhimento deve ser sempre de nivel razoável, ter um carácter acessório em relação ao objectivo científico principal da reunião e não ser alargado a pessoas que não sejam profissionais da saúde." Trata-se de preocupação descortinável também na Directiva n. 92/28/CEE, de 31 de março de 1992, nos arts. $9^{\circ}$ e $10^{\circ}$ que se tornaram mais instantes após as ocorrências deploráveis registadas no final dos anos 90 do século transacto ante a forma despudorada como se processavam relações promíscuas entre capitães de indústria e discípulos de Hipócrates. 
Os escândalos - de incalculável projecção - redundaram em processos judiciais de alcance vário, uns conclusos, outros pendentes e que buliram, com efeito, com o prestígio da classe médica, dotada, em geral, de uma aura que o sumo exercício da medicina the granjeara e de uma sacralidade levada à exclusão de eventuais responsabilidades até em hipóteses de preterição das leges artis ${ }^{(14)}$.

No quadro estrito que, entretanto e de modo imperioso, houve que refazer, ainda se conferiu suficiente margem para que os facultativos participem de eventos científicos - autênticos, autônomos e genuínos -, como extensão de uma formação para a vida (formação permanente ou contínua). Já que a alternativa seria a de se impor ao Estado assegurasse intra vires a indispensável formação a médicos, farmacêuticos e demais profissionais da saúde, se fosse o caso, ou, se de funções exclusivamente privadas se tratasse, a expensas dos próprios, como se tem por curial.

Em Portugal, o Decreto-Lei n. 48/99, de 16 de fevereiro, regrou de modo draconiano domínio tão sensível, cujos traços importa revelar ${ }^{(15)}$.

$E$ as normas então editadas não se limitaram aos facultativos, antes se estenderam aos farmacêuticos hospitalares ou de oficina que por missão têm a da dispensa de medicamentos aos pacientes, uma vez prescritos.

Daí que se haja proibido(16) dar ou prometer, directa ou reflexamente, a pessoas habilitadas a prescrever ou a dispensar medicamentos, prêmios, ofertas, benefícios pecuniários ou em espécie, excepto quando se trate de objectos relacionados com a prática da medicina ou da farmácia e de valor intrínseco insignificante.

A proibição não obsta, porém, a que o titular da autorização de introdução no mercado (AIM), bem como a empresa responsável pela promoção do medicamento (ERPM), suportem custos de acolhimento de pessoas habilitadas a prescrever ou a dispensar medicamentos em eventos científicos e acções quer de formação quer de promoção de medicamentos, desde que - em qualquer caso - tais incentivos não dependam ou constituam contrapartida da prescrição ou dispensa de fármacos.

Não obsta ainda, de análogo modo, a satisfação de honorários aos profissionais a que se alude pela participação científica activa em eventos tais. Por participação científica activa se considera a apresentação de comu-

(14) Charles Nicolle, prêmio Nobel da Medicina e professor do Colégio de França, asseverava "La société humaine délègue à certains de ses membres un mandat. Les médecins reçoivent mission de veiller à la santé des hommes. Ils exercent cette mission dans la plénitude de leur conscience. La sagesse est de s'en remettre à eux." In LEMAIRE, Jean-François; et IMBERT, Jean-Luc. "La responsabilité médicale". Paris: Presses Universitaires de France, 1985. p. 5.

(15) Que o DL n. 176/2006, de 30 de agosto, reitera, no ensejo da transposição da Directiva n. 2001/ 83/CE, do Parlamento Europeu e do Conselho, de 6 de novembro de 2001, nos seus arts. 158 e ss. (16) Ao titular da AIM ou à ERPM, se distinta daquele. 
nicações científicas, de posters ou de intervenções de qualquer natureza ou espécie no quadro das actividades de medicina ou farmácia desenvolvidas. Ponto é que os honorários deferidos, nos termos do período anterior, não constituam do mesmo passo dependência ou contrapartida da prescrição ou dispensa de medicamentos ${ }^{(17)}$.

A despeito do que nos passos precedentes se grafou, a lei veda ainda às pessoas legalmente habilitadas a prescrever e a dispensar fármacos ${ }^{(18)}$ que peçam ou aceitem de modo directo ou reflexo prêmios, ofertas, brindes ou outros benefícios pecuniários ou em espécie ao (ou do) titular da AIM e das ERPM. E tal proibição subsiste ainda que os artigos, produtos (ou o que quer que seja) procedam de qualquer outro Estado-membro ou de paises fora de tal círculo, ao abrigo de legislação estrangeira. A lei estabelece ainda, no quadro restritivo imposto em conseqüência do desalinho observado, em particular com médicos sujeitos à corrupção passiva pelos laboratórios farmacêuticos, que "sem prejuizo das atribuições e competências das entidades públicas, é proibido efectuar, por qualquer meio e a qualquer título, a recolha, o tratamento e a concessão de informações referentes à prescrição de medicamentos por determinada pessoa habilitada a prescrevê-los". Claro que neste particular é ao Instituto Nacional da Farmácia e do Medicamento, em Portugal, que incumbe uma tal atribuição e/ou competência, não sendo lícito, pois, a quem quer que seja promover tais recolhas ou estudos como forma de preservar os médicos do seu estatuto, no seu diuturno exercício.

O quadro restritivo que ora se oferece permite conciliar deveras o interesse da saúde pública, do erário público e o da formação científica proporcionada em permanência a facultativos e boticários, alvo fácil de cosmoempresas a que os interesses materiais importam particularmente, a despeito da CARTA DE RESPONSABILIDADE SOCIAL em que o primado ético se afirma de modo inequívoco e que - tantas! - , com uma hipocrisia a roçar a desfaçatez mais cruenta, subscrevem e proclamam ... para a abjurar!

(17) O n. 3 do art. 9 do DL n. 48/99, de 16 de fevereiro, era expressivo ao vedar uma tal prática: "Não constitui, igualmente, violação do $n$. 1 o pagamento, por parte do titular da autorização de introdução no mercado ou da empresa responsável pela promoção do medicamento, de honorários a pessoas habilitadas a prescrever ou a dispensar medicamentos pela participação científica activa destes, nomeadamente através da apresentação de comunicações cientificas em eventos desta natureza ou em acções de formação e de promoção de medicamentos, desde que, em qualquer caso, $o$ aludido pagamento não fique dependente ou seja contrapartida da prescrição ou dispensa de medicamentos." E o $n .1$ referia: "É proibido ao titular da autorização de introdução no mercado, bem como à empresa responsável pela promoção do medicamento, dar ou prometer, directa ou indirectamente, a pessoas habilitadas a prescrever ou a dispensar medicamentos, prémios, ofertas, benefícios pecuniários ou em espécie, excepto quando se trate de objectos relacionados com a prática da medicina ou da farmácia e de valor intrínseco insignificante." A disciplina alusiva a tal regime consta agora do art. 158 do $\mathrm{DL} n$. 176/2006, de 30 de agosto, que revoga o referenciado diploma.

(18) $E$, neste passo, registe-se que é indiferente que se trate de medicamentos sujeitos obrigatoriamente a receita médica, pois os outrora denominados, com impropriedade embora, "medicamentos de venda livre", numa tradução grosseira de OTC ("Over The Counter"), também se incluem no rol. 


\section{VI - EVENTOS CIENTÍFICOS E ACÇÕES DE FORMAÇÃO E PROMOÇÃO DE MEDICAMENTOS STRICTO SENSU}

Na rubrica precedente - ainda que de modo incidental - referência genérica ao ponto se produziu. Cumpre, no entanto, determo-nos de forma mais circunstanciada ante as exigências específicas da lei.

O titular da AIM ou a ERPM que assegure o patrocínio de acções (de formação e de promoção de medicamentos) e eventos científicos (tais como congressos, simpósios, seminários e jornadas) tem imperativamente de constar da documentação de promoção ou divulgação de tais manifestações e bem assim do rol em que figuram os participantes e dos trabalhos ou relatórios publicados após a realização de acções e eventos.

O titular da AIM e a ERPM manterão, no entanto, no departamento científico do laboratório farmacêutico de que se trata, pelo lapso de cinco anos e de molde a poderem ser sindicados a qualquer instante pelos serviços públicos competentes (Inspecção-Geral da Saúde, Instituto Nacional da Farmácia e do Medicamento, Polícia Judiciária), documentação pertinente a cada uma das acções e/ou eventos científicos que hajam sido por si patrocinados.

O documento deve, de forma completa e fidedigna, incluir os seguintes elementos: programa de acções e eventos científicos; identificação da entidade que promove, patrocina e organiza as acções em epígrafe; cópia das comunicações científicas ou de indole profissional efectuadas e mapa das despesas e eventuais receitas e respectivos documentos justificativos.

O ministro da Saúde define, por despacho, o modo de elaboração e as condições de acesso à documentação a que se alude no passo precedente sempre que em causa se ache a participação em acções (de formação e de promoção de medicamentos) e eventos científicos de quem esteja adstrito ao Serviço Nacional de Saúde. Ignora-se se a administração pública neste interim - de 1999 a esta parte - exerceu as competências que o diploma Ihe defere. No entanto, em termos pragmáticos, ou os escândalos cessaram ou, ao menos, não se configuram como tal pelo silêncio de que a comunicação social dá mostras ao longo dos 7 anos já cumpridos após os ditames oficiais vertidos a propósito. Os processos de antanho, não se acham, porém, decididos de todo, como é o caso do affaire Pequito, assim denominado pelo facto de haver sido desencadeado contra uma multinacional farmacêutica pelo delegado de informação médica, de sua graça João Pequito, de que the valeu, por óbvio, o despedimento!

\section{Encargos com o acolhimento de médicos e farmacêuticos}

Num dos pontos por que se desdobra a parte segunda do presente trabalho se aludiu que, a título excepcional, é lícito que o titular da AIM, bem 
como da ERPM suportem - parcelar ou integralmente - os custos de acolhimento em acções e/ou eventos científicos. A lei, porém, não se basta com a enunciação genérica do ponto. $E$ vai ao extremo de recortar de forma extensa e profunda o conceito. Aí se considera qualquer dos encargos emergentes da inscrição, deslocação e estada em manifestações de carácter exclusivamente científico e ainda em acções de formação e promoção de fármacos (ou produtos farmacêuticos, maxime, de medicamentos) que comportem uma efectiva mais-valia científica ou um real proveito formativo para os respectivos participantes. estada.

E a lei vai anda mais longe: define o dies a quo e o dies ad quem da

"A estada não deverá exceder o período compreendido entre o dia anterior ao do início e o dia seguinte ao do termo do evento ou das acções de formação ou de promoção de medicamentos nem comportar benefícios de carácter social, prevalentes sobre o objectivo científico e profissional".

A ratio legis é a de evitar que o denominado turismo médico, tão em voga no período em que os escândalos estalaram, prosseguisse de forma equívoca ou dissimulada, com prejuizos manifestos quer para a assiduidade dos prescritores e dispensadores de medicamentos, com reflexos na saúde individual e colectiva das pessoas, quer para o reforço do saber dos destinatários das acções e eventos.

$\mathrm{Na}$ realidade, os laboratórios foram incriminados por propiciarem o "turismo médico" de forma generalizada e/ou de presentearem, sobretudo os médicos, com uma gama de electrodomésticos para uso pessoal de renomadas marcas e de modelos de eleição como contrapartida para a prescrição de fármacos determinados.

O que obriga ainda que se defina o perfil do "acolhimento", sempre de "nivel razoável e ter um carácter acessório em relação ao objectivo principal da reunião, não devendo ser alargado a pessoas que não sejam profissionais de saúde destinatários dos mesmos".

Neste passo o que se visa é evitar que os familiares, como soía acontecer, se aproveitem também, de modo directo ou reflexo, das deslocações com intuitos científicos ou formativos para se avantajarem com benefícios que decorrem da oferta de digressões turísticas que se proporcionam a latere a cônjuges, acompanhantes, descendentes, parentes outros ou afins. A lei é restritiva e põe ponto final nas promiscuidades que também aí se detectavam de modo incontroverso.

As exigências postam-se ainda a outros niveis, nomeadamente ou especificamente no que tange aos locais em que decorrem acções e eventos. As opções pelos locais em que se consumarão as acções de formação e promoção e os eventos científicos e a organização dos programas sociais 
complementares, se os houver, mister será que obedeçam a critérios adequados de uma perspectiva laboral e científica. Mas força é que envolvam também - no que a níveis de hospitalidade se refere, designadamente custos financeiros de montante equilibrado, como prescreve a lei, numa contenção de gastos que não exorbite dos objectivos imbricados nas acções sub judice.

À administração pública cabe assegurar-se da observância das prescrições em realce, importando significar que o afrontamento a tais normas constitui ilícito de mera ordenação social passível de coima susceptível de atingir cerca de 45 mil Euros.

\section{VII - CÓDIGOS DEONTOLÓGICOS DA INDÚSTRIA FARMACÊUTICA LATO SENSU}

Ante o deprimente quadro que se nos deparou em Portugal a propósito das relações promiscuas entre os laboratórios da indústria farmacêutica e os médicos, a associação de interesses econômicos que agrega as distintas unidades de produção em laboração no País apressou-se a definir, em termos auto-regulatórios, regras de feição deontológica que passaram, entretanto, a vigorar nas relações inter partes. Para além do Convênio que a Federação Européia das Indústrias Farmacêuticas e o Comitê Europeu dos Médicos celebraram. E que assumem, de resto, carácter transnacional, à dimensão européia.

Os termos firmados entre a European Federation of Pharmaceutical Industries and Associations (EFPIA) e o Standing Comittee of European Doctors (CPME) constam de um convênio de boa vontade alçado a Código Deontológico com repercussões na esfera de cada um dos subscritores e valimento intra muros de cada um dos Estados-membros da União Européia.

Aí se aparelham medidas tendentes a subtrair às relações entretecidas o espectro de suspeição que constituiu, em múltiplos cenários, a dominante na promiscuidade subsistente, a macular de forma impressiva a reputação e a fidedignidade dos facultativos. E é óbvio que se não pode tomar a nuvem por Juno ou confundir a árvore com a floresta. No entanto, os aspectos desviantes puseram em causa - e em geral - a imagem que o vulgo tinha dos médicos.

Dentre os deveres a que se adscreve a indústria, figura no texto que se impõe inter pares no espaço preenchido pela União Europeia, o de não oferecer hospitalidade injustificada. Além disso, os brindes/benefícios não devem ser dispendiosos e têm de estar associados à prática clínica.

Aos médicos, no documento de que se trata, incumbe, porém, não solicitar brindes/benefícios à indústria e não aceitar hospitalidade injustificada; os brindes/benefícios não devem ser dispendiosos e devem estar associados à prática clínica. 
Às reuniões sob a égide ou o patrocínio da indústria (ou em que se coenvolva ou promova) presidem regras muito estritas, a saber:

- as Companhias Farmacêuticas podem organizar ou patrocinar reuniões médicas: tais eventos devem ter uma vertente/componente claramente pedagógica; a informação transmitida em qualquer reunião deverá ser baseada em dados médicos e científicos relevantes;

- actividades que façam parte do desenvolvimento profissional contínuo e sistemático devem ser avaliadas e certificadas por entidades relevantes;

- quando da divulgação, o objectivo do evento deve ser devidamente especificado: quando apropriado, será também indicado se o evento é avaliado e certificado;

- o local da reunião deve ser apropriado para o objectivo científico da reunião e não deverá envolver deslocações além das necessárias;

- a Indústria Farmacêutica poderá pagar a palestrantes, material de estudo e instalações necessárias para a realização da reunião: poderá também pagar a viagem e o alojamento dos participantes, mas não o dos acompanhantes;

- a recepção durante as reuniões deve ser aceitável na generalidade, razoável e estritamente limitada ao objectivo do evento: patrocinar ou organizar eventos desportivos ou de entretenimento está proibido.

A Indústria Farmacêutica, em Portugal, elaborou, entretanto, um Código Deontológico que rege as práticas promocionais dos produtos que lançou no mercado, datado de 28 de setembro de 2005.

Nos arts. 13 e seguintes se espraiam as regras estabelecidas em especificos domínios, a saber, eventos e hospitalidade, ofertas e incentivos, patrocínio de profissionais de saúde e amostras (de fármacos). E aí se plasmam regras estritas que, no tocante a eventos científicos, se compaginam com os que os instrumentos internacionais e a lei em vigor em Portugal imperativamente consagram.

Cumpre reter a tal propósito que todas as reuniões, congressos, conferências, simpósios e outros eventos de natureza promocional, científica ou profissional ("evento") organizados ou patrocinados por uma empresa titular de autorização de introdução no mercado ou promotora de um medicamento têm de ser realizados num local adequado condizente com o fim principal do evento, e só podem proporcionar hospitalidade quando a mesma for adequada e cumprir as disposições legais em vigor.

Acrescente-se que nenhuma empresa pode organizar ou patrocinar eventos que se realizem fora do seu pais de origem ("evento internacional"), 
salvo se a maior parte dos participantes for de fora do país de origem $e$, tendo em conta os paises de origem da maior parte dos convidados, fizer mais sentido em termos lógicos realizar o evento noutro país; ou ainda, considerando-se que a localização dos recursos ou conhecimentos relevantes que constituem o objecto ou tema do evento, fizer mais sentido em termos lógicos realizar o evento noutro país.

A hospitalidade proporcionada em relação a eventos promocionais, profissionais ou científicos deve restringir-se às viagens, refeições, alojamento e custos de inscrição; todavia, os aspectos sociais e ou estritamente culturais que possam complementarmente existir não podem de qualquer forma coincidir com qualquer reunião de trabalho. Ela não deverá exceder o periodo compreendido entre o dia anterior ao início e o dia seguinte ao do termo do evento, e só pode ser oferecida a profissionais de saúde que sejam participantes por direito próprio.

Também, esta hospitalidade proporcionada a profissionais de saúde deve ter um nível razoável e restringir-se estritamente ao objectivo principal do evento. Como regra geral, ela não deve exceder o que os profissionais de saúde participantes no evento estariam preparados para pagar eles próprios e não pode incluir o patrocínio ou a organização de eventos com carácter de entretenimento ( $v$.g. desportivos ou de diversão), e as empresas devem evitar escolher locais/empreendimentos conhecidos pelas suas instalações para diversão.

No que tange a brindes, ofertas, prêmios e incentivos, realça-se o fato de que não podem ser fornecidas, oferecidas ou prometidas ofertas, vantagens pecuniárias ou benefícios em espécie aos profissionais de saúde, que de qualquer forma, directa ou indirectamente, os incentive a prescrever, fornecer, vender ou administrar um medicamento. Sem prejuízo do disposto no número anterior, nos casos em que os medicamentos sejam promovidos junto de profissionais de saúde, podem ser fornecidos ou oferecidos benefícios em espécie a essas pessoas, unicamente se forem de baixo valor pecuniário e relevantes para a prática da medicina ou farmácia e/ou envolvam um benefício para o doente. As ofertas podem conter apenas o nome e logotipo da empresa, o nome do medicamento e/ou a sua denominação comum internacional, quando esta exista, ou a marca comercial. Se com elas se pretender dar informação adicional sobre o medicamento, esta tem que observar o disposto particular da AIM. Não devem ser oferecidas nem proporcionadas ofertas para benefício pessoal dos profissionais de saúde, tais como bilhetes para eventos de entretenimento.

Entende-se por baixo valor pecuniário um valor que não deverá exceder um quarto de unidade de conta de custas judiciais ${ }^{(19)}$.

(19) Ora fixada em 88 Euros. 
O patrocínio de manifestações científicas segue estrita prescrição, a saber, a do art. 15, pelo qual sempre que uma empresa patrocine um simpósio, congresso ou qualquer outro programa de saúde, médico ou educacional, deverá levar em consideração os seguintes princípios:

- o patrocínio deve ser claramente anunciado previamente ao acontecimento identificado, durante o mesmo e na fase pós-realização. Todo e qualquer material de informação, impresso, audiovisual ou informático que saia de tais encontros, deve reflectir correctamente as comunicações e discussões;

- o apoio à participação a profissionais de saúde não deve estar condicionado à obrigação de promover qualquer medicamento;

- se o programa for reconhecido para efeitos de formação profissional pós-licenciatura, por organização médica reconhecida ou outra qualquer organização de profissionais de saúde, igualmente reconhecida, deverá ser revelado, se o houver, o apoio da Indústria Farmacêutica;

- é considerado adequado o pagamento de honorários e o reembolso de despesas, incluindo viagens, aos oradores e moderadores dos encontros.

No particular das amostras, o regime é, conformemente à directiva, estrito. Assim, as amostras só serão fornecidas a instâncias do médico, não poderão ser maiores que a apresentação menor lançada no mercado e terão de conter a menção "amostra médica grátis - venda proibida". Além disso, as empresas disporão de sistemas de controle e contabilização das amostras.

Há também restrições no que tange à própria natureza dos fármacos e, dessa maneira, proíbe-se a doação de medicamentos que contenham substâncias definidas como psicotrópicas ou estupefacientes por uma convenção internacional, tal como as Convenções das Nações Unidas de 1961 e 1971, e outros medicamentos para os quais não seja adequado fornecer amostras, tal como determinado pelas autoridades competentes em cada momento.

A relevância do tema avulta em momento em que a dissolução dos valores grassa por toda a parte e paradigmas outros mesclados de poderosos interesses egoísticos tendem a sobrepujar os bens, interesses ou valores jurídicos fundamentais imbricados na saúde pública.

Ponto é que não campeie a hipocrisia institucional na concreta aplicação dos normativos, quer se trate dos que emanam de instâncias legiferantes nacionais e/ou internacionais ou da soft law a que as associações, soidisant de classe e as de interesses econômicos, conferem expressão para observância inter partes. 
Ponto é que haja suficiente vigor para contrariar as violações que amiúde ocorrem e os desvios deploráveis a que se assiste numa reverberável subversão dos quadros e dos propósitos neles consignados.

\section{VIII - A PUBLICIDADE AO MEDICAMENTO E CONEXOS NO ANTEPROJECTO DO DENOMINADO CÓDIGO DO CONSUMIDOR}

Ao domínio de que se cura, o anteprojecto português, ora em debate, consagra, em rigor, um só artigo - o 104.

Nele se contém o comando que segue:

"É proibida a publicidade a tratamentos médicos e a medicamentos que apenas possam ser obtidos mediante receita médica, com excepção da publicidade incluída em publicações técnicas destinadas a médicos e outros profissionais de saúde."

No entanto, à semelhança do que ora ocorre com o Código da Publicidade em vigor no ordenamento jurídico nacional, e no que tange, em geral, à saúde, dispõe o normativo em epígrafe, no art. 97, o que segue:

"1. É proibida a publicidade que encoraje comportamentos prejudiciais à saúde ou à segurança, designadamente por deficiente informação acerca da perigosidade do produto ou da especial susceptibilidade da verificação de acidentes em resultado da utilização que lhe é própria.

2. A publicidade não deve comportar qualquer apresentação visual ou descrição de situações onde a segurança não seja respeitada, salvo justificação de ordem pedagógica.

3. O disposto nos números anteriores deve ser particularmente acautelado no caso da publicidade especialmente dirigida a crianças, adolescentes, idosos ou deficientes."

E no que se prende com os efeitos benéficos de produtos e serviços milagrosos, realce para o que o art. 98 do anteprojecto encerra ("menção de efeitos benéficos"), a saber:

"Sem prejuizo da aplicação geral das disposições relativas à publicidade enganosa, são especialmente proibidas as menções a efeitos benéficos para a saúde ou para o ambiente, feitas com o intuito de promover produtos ou serviços, cuja veracidade não esteja cientificamente comprovada."

E no que se refere a produtos e serviços milagrosos, confira-se 0 art. 109 que, em sentido análogo ao do art. $22^{\circ}-\mathrm{B}$ do Código da Publicidade, é do teor seguinte: 
"1. É proibida, sem prejuizo do disposto em legislação especial, a publicidade a bens ou serviços milagrosos.

2. Considera-se publicidade a bens ou serviços milagrosos, para efeitos da presente secção, a publicidade que, explorando a ignorância, o medo, a crença ou a superstição dos destinatários, apresente quaisquer bens, produtos, objectos, aparelhos, materiais, substâncias, métodos ou serviços como tendo efeitos específicos automáticos ou garantidos na saúde, bem-estar, sorte ou felicidade dos consumidores ou de terceiros, nomeadamente por permitirem prevenir, diagnosticar, curar ou tratar doenças ou dores, proporcionar vantagens de ordem profissional, económica ou social, assim como alterar as caracteristicas físicas ou a aparência das pessoas, sem uma objectiva comprovação científica das propriedades, características ou efeitos propagandeados ou sugeridos.

3. O ónus da comprovação científica a que se refere o número anterior recai sobre o anunciante.

4. As entidades competentes para a instrução dos processos de contra-ordenação e para a aplicação das medidas cautelares e das coimas podem exigir que o anunciante apresente provas da comprovação científica a que se refere o $n$. 2, bem como da exactidão material dos dados de facto e de todos os benefícios propagandeados ou sugeridos na publicidade.

5. A comprovação científica a que se refere o $n$. 2, bem como os dados de facto e os benefícios a que se refere o número anterior, presumemse inexistentes ou inexactos se as provas exigidas não forem imediatamente apresentadas ou forem insuficientes."

A televisão é, em particular, visada pelas restrições do anteprojecto, nele se plasmando (vendas à distância: pela televisão) doutrina segundo a qual:

"1. Considera-se televenda, para efeitos da presente secção, a difusão de ofertas directas ao público, realizada por canais televisivos, com vista ao fornecimento de produtos ou à prestação de serviços, incluindo bens imóveis, direitos e obrigações, mediante remuneração.

2. São aplicáveis à televenda, com as necessárias adaptações, as disposições previstas nesta seç̧ão para a publicidade, sem prejuizo do disposto nos números seguintes.

3. É proibida a televenda de medicamentos sujeitos a uma autorização de comercialização, assim como a televenda de tratamentos médicos.

4. A televenda não deve incitar os menores a contratarem a compra ou aluguer de quaisquer bens ou serviços." 
O Código da Publicidade, transposto para o anteprojecto do denominado Código do Consumidor, não é, pois, pródigo em normas pertinentes à publicidade do medicamento. As disposições que se the referem constam de diploma autônomo: in casu o DL n. 176/06, de 30 de agosto, que reúne a maior parte dos dispositivos em que se plasma o regime jurídico do medicamento. Afigura-se-nos, porém, que o Código de Direitos do Consumidor, na sua versão definitiva, deveria comportar o regime inteiro da publicidade, independentemente da natureza dos produtos e serviços em especial. E não é essa, ao que parece, a orientação, com inúmeros aspectos parcelares a eximir-se do diploma matriz do estatuto do consumidor.

\section{IX - CONCLUSÃo}

A publicidade aos medicamentos de uso humano (alopáticos como homeopáticos) está, no seio da União Européia, disciplinada por uma directiva que veda mensagens dirigidas ao grande público de medicamentos sujeitos obrigatoriamente à receita médica.

Tais medicamentos podem, porém, ser objecto de publicidade em publicações exclusivamente destinadas a profissionais de saúde de distintos estratos com tal co-relacionados.

A publicidade, porém, de medicamentos não sujeitos à receita médica é livre, conquanto a lei estabeleça condicionantes, na esteira, de resto, da natureza não intrinsecamente mercantil dos fármacos, indissoluvelmente imbricados na saúde pública e cuja dispensa exige peculiares cuidados.

No que tange, porém, aos prêmios, ofertas, brindes e mais benefícios, também é vedado dar ou prometer, como pedir ou aceitar, ainda que a praxis, noutros paises, seja permissiva, com ou sem suporte nos ordenamentos de origem.

No domínio das acções de formação e de promoção de medicamentos e bem assim no dos eventos científicos em que se congregam médicos e ou farmacêuticos, quer os honorários pela apresentação de comunicações científicas ou outras, quer os encargos advenientes da inscrição, deslocação e estada susceptíveis de ser assegurados pelos titulares da AIM e da ERPM, são lícitos, desde que se observem condições de transparência que a administração pública põe a cargo tanto de quem assume o patrocínio como de quem realiza sob sua égide tais manifestações de formação, promoção ou de indole científica tout court.

As condições estabelecidas obedecem a critérios de transparência, de adequação e proporcionalidade, que a lei fixa de forma estrita.

É vedado alargar o benefício da deslocação e do alojamento (e o mais) a quaisquer pessoas que se situem fora da órbita das manifestações de que 
se trata por forma a encerrar definitivamente o "turismo médico" a lugares privilegiados de vilegiatura que se proporcionava em larga escala, sobretudo a médicos, familiares e ou a acompanhantes outros.

As associações européias de médicos e as das indústrias farmacêuticas coenvolveram-se em iniciativas auto-regulatórias tendentes a consignar regras de conduta assentes no plano ético de molde a não desvirtuar a natureza das coisas e a não permitir que os interesses materiais subvertam as directrizes mais adequadas.

O anteprojecto do denominado Código do Consumidor reitera, em múltiplas normas, preocupações do estilo e veda, em geral, a publicidade a medicamentos, como a que encoraja comportamentos nocivos à saúde ou à segurança, como as menções a efeitos benéficos para a saúde com o intuito de promover produtos ou serviços, como ainda a produtos ou serviços miraculosos, em exploração da ignorância, medo, crença ou superstição do universo-alvo a que se dirija.

A prossecução de esforços em ordem à tutela de tais princípios e valores é missão essencial para que se convocam, sem reservas nem tergiversações, os cidadãos-consumidores.

\section{$X$ - ANEXOS}

\section{REFERÊNCIAS}

SANTOS, Beja. In: Diário de Aveiro: ed. $1^{9}$ set.

NICOLLE, Charles. In Jean-François Lemaire et Jean-Luc Imbert, La Responsabilité Médicale. In: LEMAIRE, Jean-François, IMBERT, Jean-luc. Presses Universitaires de France, Paris, mai 1985. 